\title{
Pseudonocardia Symbionts of Fungus-Growing Ants and the Evolution of Defensive Secondary Metabolism
}

\author{
Sarah L. Goldstein and Jonathan L. Klassen* \\ Department of Molecular and Cell Biology, University of Connecticut, Mansfield, CT, United States
}

Actinobacteria belonging to the genus Pseudonocardia have evolved a close relationship with multiple species of fungus-growing ants, where these bacteria produce diverse secondary metabolites that protect the ants and their fungal mutualists from disease. Recent research has charted the phylogenetic diversity of this symbiosis, revealing multiple instances where the ants and Pseudonocardia have formed stable relationships in which these bacteria are housed on specific regions of the ant's cuticle. Parallel chemical and genomic analyses have also revealed that symbiotic Pseudonocardia produce diverse secondary metabolites with antifungal and antibacterial bioactivities, and highlighted the importance of plasmid recombination and horizontal gene transfer for maintaining these symbiotic traits. Here, we propose a multi-level model for the evolution of Pseudonocardia and their secondary metabolites that includes symbiont transmission within and between ant colonies, and the potentially independent movement and diversification of their secondary metabolite biosynthetic genes. Because of their well-studied ecology and experimental tractability, Pseudonocardia symbionts of fungus-growing ants are an especially useful model system to understand the evolution of secondary metabolites, and also comprise a significant source of novel antibiotic and antifungal agents.

Keywords: Pseudonocardia, attine ant mutualism, evolution, symbiosis, specialized (secondary) metabolite

\section{INTRODUCTION}

Actinomycete bacteria form many beneficial symbioses with eukaryotes, where the host typically provides nutritional support and the actinomycetes provide chemical defense (Van Arnam et al., 2018). The best-studied of these are insect-actinomycete mutualisms, which are widespread and the source of many novel secondary metabolites with antibacterial and antifungal activity (Chevrette and Currie, 2019). Insect-associated Streptomyces inhibited clinically relevant microbes more effectively than soil-isolated Streptomyces (Chevrette et al., 2019), perhaps due to co-evolution between insects and microbes that has selected for defensive metabolites inhibiting pathogens but not their hosts (Clardy et al., 2009). The potential rise of antimicrobial resistance in these symbioses must have also been overcome by selection consistently replenishing and diversifying their defensive metabolites. However, few systems exist where such ecological and evolutionary dynamics have been dissected in detail. 


\section{FUNGUS-GROWING ANTS: A MULTIPARTITE MUTUALISM}

Fungus-growing (Attine) ants are one of the best-studied insectmicrobe symbioses, encompassing $>250$ described species from 17 genera (Schultz and Brady, 2008; Sosa-Calvo et al., 2018) that inhabit a geographic range stretching from the tip of Argentina to Long Island, New York, United States (Weber, 1972). Approximately 50-60 million years ago, these ants established a symbiotic relationship with a "cultivar" fungal symbiont that they farm in underground fungus gardens (Mueller et al., 1998). Fungus-growing ants provide fresh leaves (especially in the most-specialized leaf-cutting ants), grass clippings, fruits, berries, flowers, and insect frass to their fungal cultivar (De Fine Licht and Boomsma, 2010), which is the ants' obligate food source. The cultivar relies on the ants for vertical propagation, and has lost its ability to reproduce sexually via spores (Weber, 1972). Virgin ant queens take a small piece of cultivar fungus from their native nests with them during their nuptial mating flights and use it establish their new colonies, propagating the fungal cultivar in a largely clonal fashion (Mueller et al., 1998). It was originally believed that no other fungi were present in ant fungus gardens due to the effects of antimicrobials that the ants secrete (Hölldobler and Wilson, 1990) and their extensive grooming behaviors (Currie and Stuart, 2001). However, Currie et al. (1999a) demonstrated the persistent presence of a specialized fungal parasite Escovopsis within ant fungus gardens that is highly pathogenic toward the cultivar fungus, and suggested that the fungus-growing symbiosis be expanded to include the ants, their cultivar, and the Escovopsis fungal pathogen as a coevolving tripartite symbiosis (Currie et al., 2003c). Future research will likely clarify the conditions under which Escovopsis acts as such a pathogen, and the impact of other pathogens in this symbiosis.

Concurrent with the discovery of the fungal pathogen Escovopsis, Currie et al. (1999b) also established that an actinomycete bacterium comprises a fourth partner in the fungus-growing ant symbiosis. Many fungus-growing ant species have a region of their cuticle that is covered by a white or gray crust (Figure 1), which was initially described as a "waxy bloom" and dismissed as a cellular exudate (Weber, 1972). Upon closer inspection using scanning electron microscopy and targeted microbial isolations, this crust was subsequently determined to be a biofilm formed by the actinomycete Pseudonocardia (albeit initially misidentified as Streptomyces; Currie et al., 1999b, 2003b; Cafaro and Currie, 2005). These Pseudonocardia are housed in specialized structures on the ant cuticle that are connected to ant exocrine glands (Poulsen et al., 2003; Currie et al., 2006; Li et al., 2018), and their growth may be upregulated when an ant colony is under attack by Escovopsis (Currie et al., 2003a). Pseudonocardia symbionts can be parasitized by black yeast that compete with them for nutrients on the ant-cuticle, suppressing the growth of Pseudonocardia (Little and Currie, 2007). Such parasitism makes the fungus garden more susceptible to fungal infection, highlighting Pseudonocardia's contribution to maintaining ant colony health (Little and Currie, 2008).

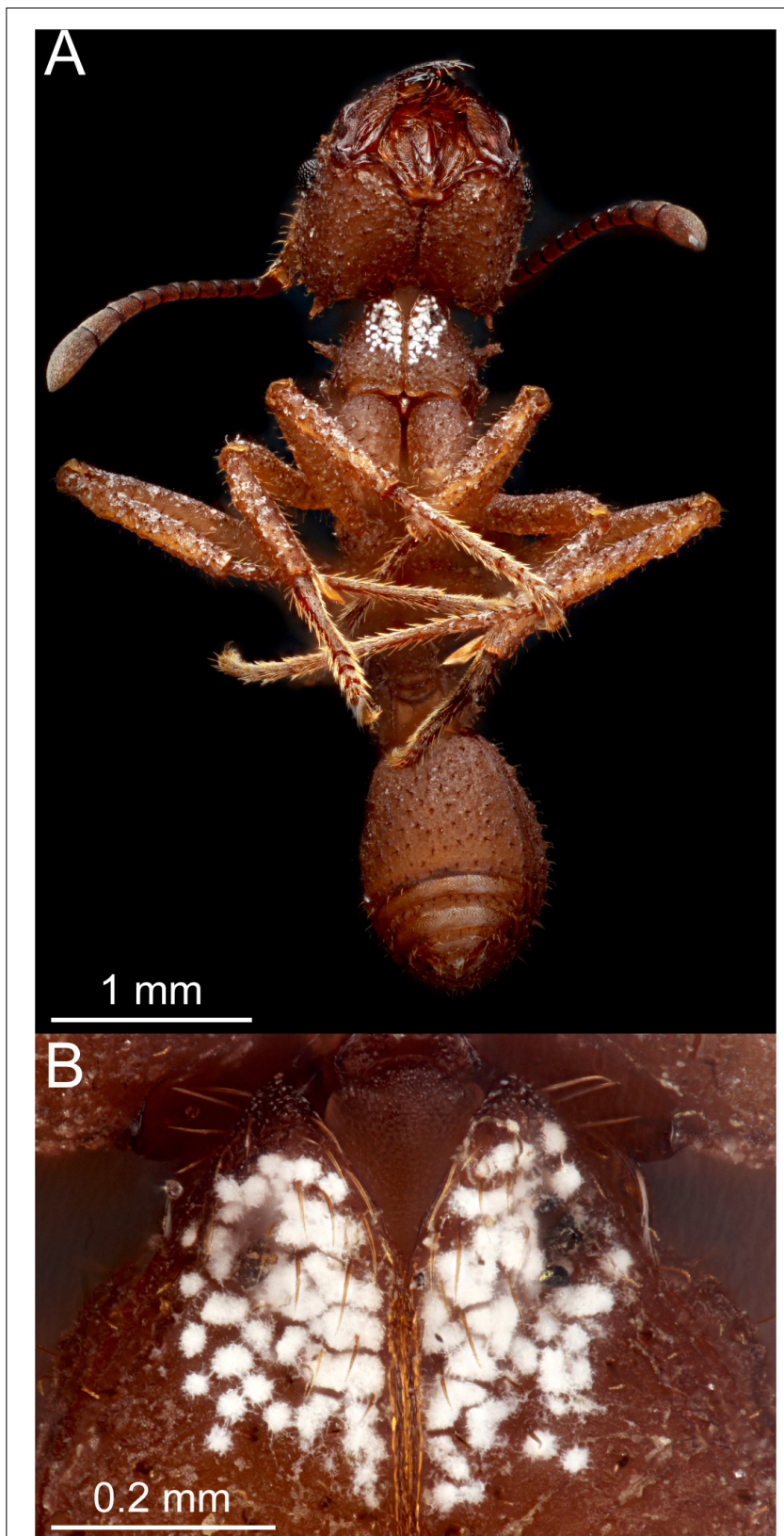

FIGURE 1 | (A) Ventral view of an adult Trachymyrmex septentrionalis worker ant, showing the localization of Pseudonocardia (white patches) on the laterocervical plates that is typical of adult worker ants. (B) Enlargement of the laterocervical plates from (A). Photo credit: Mark Smith, Macroscopic Solutions; used with permission.

\section{PSEUDONOCARDIA AS A DEFENSIVE SYMBIONT}

Increased abundance of Pseudonocardia on ants in response to parasite infection underscores the predicted function of this bacterium in the system: to protect the fungal cultivar against Escovopsis (Currie et al., 1999b, 2003a). Pseudonocardia prevent Escovopsis infections of ant fungus gardens in vivo 
(Currie et al., 2003a; Little and Currie, 2008; Poulsen et al., 2010), and Pseudonocardia isolates consistently inhibit Escovopsis cultures in vitro (Currie et al., 1999b, 2003a; Schoenian et al., 2011; Meirelles et al., 2013; Sit et al., 2015; Dângelo et al., 2016). Some researchers have therefore suggested that these symbionts co-evolve with one another, locked in an arms race where Pseudonocardia and Escovopsis constantly evolve new mechanisms to gain an advantage over each other (Woolhouse et al., 2002). However, Pseudonocardia defenses against Escovopsis can vary (Poulsen et al., 2010), and some fungus-growing ants are not pathogenized by Escovopsis (Rodrigues et al., 2008), despite hosting Pseudonocardia. Further studies have shown that Pseudonocardia isolates have broad-spectrum activities against fungi other than just Escovopsis (Sen et al., 2009; Meirelles et al., 2013; Dângelo et al., 2016), suggesting that Pseudonocardia's antimicrobials inhibit diverse pathogens in the fungus-growing ant symbiosis.

Pseudonocardia strains can also inhibit entomopathogens that infect the ants (Sen et al., 2009; Mattoso et al., 2012), to which ants are inevitably exposed to as they excavate tunnels, tend to brood, or forage for plant matter (Hughes et al., 2004, 2009). Although the ants themselves possesses an innate immune system that can defend against pathogens (Gillespie et al., 1997), and engage in allogrooming to reduce the potential for infection (Walker and Hughes, 2009), Pseudonocardia may add further protection against ant pathogens (de Souza et al., 2013). Pseudonocardia abundance peaks at 10-15 days post-eclosion before declining (Poulsen et al., 2003), and so Pseudonocardia may therefore particularly confer protection to young workers by giving their immune systems time to develop and recognize entomopathogens, in addition to protecting the fungal cultivar against Escovopsis (de Souza et al., 2013).

\section{PSEUDONOCARDIA SYMBIONT TRANSMISSION AND SPECIFICITY}

Pseudonocardia are thought to typically be transmitted vertically, similar to the fungal cultivar. Pseudonocardia symbionts were detected on foundress ant queens, but not on male alates, during their nuptial flights (Currie et al., 1999b). Pseudonocardia were also identified on virgin queens within their native nests, but not on males (Currie et al., 1999b), suggesting that founding queens need to maintain Pseudonocardia to successfully establish new colonies. Once a colony is established, Pseudonocardia are transmitted vertically to new workers within $2 \mathrm{~h}$ of eclosing via contact with an older worker ant that has an established Pseudonocardia biofilm, after which time vertical transmission is drastically reduced (Marsh et al., 2014). Vertical transmission of Pseudonocardia, therefore occurs both within and between ant colonies.

Phylogenetic studies have also revealed an evolutionary history of ant-associated Pseudonocardia that is largely, but not exclusively, consistent with vertical transmission. Most fungusgrowing ant colonies maintain a single strain of Pseudonocardia (Poulsen et al., 2005; Andersen et al., 2013), and this specificity can be maintained in the lab for at least 10 years (Andersen et al.,
2013). Consistent with the dominance of vertical transmission, Cafaro et al. (2011) observed significant, but not absolute, patterns of specificity between lineages of Pseudonocardia and their ant host genera using a multi-locus gene phylogeny. Subsequent studies indicated that the Pseudonocardia-ant symbiosis has been gained and lost multiple times during ant evolution ( $\mathrm{Li}$ et al., 2018), the most notable of these being the loss of Pseudonocardia in the highly derived Atta leaf-cutting ants (but see Marsh et al., 2013). Pseudonocardia symbionts of Apterostigma dentigerum ants have population structures that are consistent with vertical transmission between their dispersallimited hosts (Caldera and Currie, 2012; Mcdonald et al., 2019), but similar population structures were not detected for Pseudonocardia symbionts of Trachymyrmex septentrionalis ants using methods with lower phylogenetic resolution (Mikheyev et al., 2008). Ants can recognize their native Pseudonocardia symbiont (Zhang et al., 2007; Poulsen et al., 2011), and experimental symbiont swaps decrease symbiont abundance and ant grooming behavior, thereby allowing increased pathogen infection (Armitage et al., 2011; Andersen et al., 2015). These results show that Pseudonocardia can be adapted to their specific ant hosts and vice versa, as expected from a predominantly vertical mode of transmission, although symbiont replacement remains possible.

Like many microbial symbionts (Garcia and Gerardo, 2014), the fitness benefits that Pseudonocardia gain from their relationship with fungus-growing ants remains unclear. Although exocrine gland secretions have been speculated to feed Pseudonocardia symbionts (Currie et al., 2006), this has not been demonstrated unequivocally. The vertical transfer of Pseudonocardia between ant generations implies fitness benefits that are received by these bacteria (otherwise the relationship would be expected to break down). However, Pseudonocardia presence varies between related ant species (Fernández-Marín et al., 2013) and genera (Li et al., 2018), indicating that the benefits of this relationship change over time. Further research is warranted to determine the conditions under which selection favors Pseudonocardia and/or their ant hosts, and how potential conflicts between these partners are resolved, which will define when and if Pseudonocardia functions as an ant mutualist, commensal, or parasite.

The predicted function of Pseudonocardia as a defensive symbiont provides an evolutionary incentive for ant colonies to maintain effective Pseudonocardia strains. There is a fitness cost for an ant to swap symbionts if a less effective strain replaces a more effective one (Sachs et al., 2011). However, strict maintenance and vertical transmission of clonal symbionts can lead to other potential problems, such as Muller's ratchet, which predicts that a symbiont is ultimately doomed to extinction due to the accumulation of deleterious mutations in the absence of recombination or symbiont replacement (Bennett and Moran, 2015). Considering that Pseudonocardia symbionts of fungusgrowing ants were observed in a piece of 15 million year old amber ( $\mathrm{Li}$ et al., 2018), it is likely the ant-Pseudonocardia symbiosis has been conserved over long evolutionary timescales, despite the predominantly vertical transmission of clonal symbiont populations. 


\section{CHALLENGING PSEUDONOCARDIA SPECIFICITY AND CLONALITY}

How then does this ant-actinomycete symbiosis maintain enough diversity to avoid extinction or the loss of their defensive function? One hypothesis is that actinomycetes other than Pseudonocardia are also maintained as defensive symbionts of ants. Several studies have isolated such actinomycetes from fungus-growing ants and showed that they inhibit fungal pathogens in vitro (Kost et al., 2007; Mueller et al., 2008; Haeder et al., 2009; Sen et al., 2009; Barke et al., 2010; Dângelo et al., 2016). Schoenian et al. (2011) also found compounds known to be produced by Streptomyces strains on the cuticle of Acromyrmex ants, concluding that those actinomycetes were therefore ant symbionts. However, these studies have limitations that constrain their ability to unambiguously assign a symbiotic relationship or defensive function to these actinomycetes (Klassen, 2014, 2018, 2020). First, they typically sample few ant colonies, in contrast to the systematic sampling of Pseudonocardia that shows its widespread relationship with fungus-growing ants (Cafaro et al., 2011; Li et al., 2018). Such limited sampling cannot differentiate persistent symbionts from more transient microbial contaminants. Second, the widely used culture-based techniques are largely qualitative and can misrepresent the dominant taxa in samples (Andersen et al., 2013), instead leading to a focus on lowabundance microbes due to enrichment biases. Third, samples taken from whole ants instead of the specific locations where Pseudonocardia are known to localize (Figure 1) can introduce contaminants that mask the dominance of Pseudonocardia and its products in their more specific niche (Andersen et al., 2013; Gemperline et al., 2017). Thus, although it may be true that other actinomycetes occur in the fungus-growing ant symbiosis and produce secondary metabolites, additional evidence is required to confirm their functional role as fungus-growing ant symbionts and to rule out alternative interpretations such as transient contamination of ant colonies (Klassen, 2014, 2018, 2020).

The clonality of Pseudonocardia symbionts within individual ant colonies has also been challenged. Culture-dependent and -independent 16S rRNA gene amplicon sequencing of T. septentrionalis-associated Pseudonocardia found an average of 2.9 strains of Pseudonocardia per ant (Ishak et al., 2011). However, this study sampled whole ants and ant sections instead of specifically targeting the propleural plates where Pseudonocardia is localized, perhaps including transient bacteria from within the ant and elsewhere on the cuticle. These criticisms also apply to similar studies (e.g., Sen et al., 2009), including those that sampled Pseudonocardia from ant fungus gardens instead of from on the ants themselves (e.g., Mueller et al., 2008). In contrast, laterocervical plates dissected from Acromyrmex echinatior ants with the remaining internal soft tissue removed prior to $45416 \mathrm{~S}$ rRNA gene pyrosequencing hosted single Pseudonocardia strains in 25 of 26 ants sampled (Andersen et al., 2013), consistent with the prevalence of clonal Pseudonocardia populations in most, but not all, fungus-growing ant colonies. Finally, it is important to note that these and related studies investigating the clonality and transmission of Pseudonocardia strains (e.g., Mueller et al., 2010) have relied on the partial sequencing of housekeeping genes that contain limited phylogenetic information and that are often superseded by the higher resolution provided by whole genome sequencing, which is able to more precisely resolve species and population-level differences (e.g., Mcdonald et al., 2019).

\section{COMPETITION MAY DRIVE HORIZONTAL GENE TRANSFER}

Despite the issues described above, the presence of other actinomycetes in association with fungus-growing ants should not be discounted. Pseudonocardia isolates may be maintained and vertically propagated in this symbiosis while also acquiring genetic diversity, particularly secondary metabolite biosynthetic gene clusters (BGCs), via genetic exchange with other environmental actinomycetes. This strategy would allow Pseudonocardia to avoid the consequences of strict vertical transmission, such as Muller's ratchet, and to increase their fitness by acquiring BGCs from other actinomycetes to overcome pathogen resistance. The ability to acquire BGCs may represent a preadaptation that makes Pseudonocardia an especially successful symbiotic partner (Toft and Andersson, 2010). Horizontal acquisition of defensive genes may also provide Pseudonocardia with the ability to compete against other strains that seek to colonize the ant host (Sachs et al., 2011). This ability to inhibit other actinomycetes may even have given rise to the vertical propagation of specific Pseudonocardia lineages, allowing what may have initially began as a parasitic relationship to transition to a mutualism (Sachs et al., 2011). Other theoretical models have suggested that such competition between actinomyces may actively select for Pseudonocardia that produce high levels of bioactive compounds on the ants (Scheuring and Yu, 2012), although it should be noted that the antibacterial compounds deployed for competition between bacteria are likely to differ from those that mediate antifungal defense.

Native Pseudonocardia strains inhibit the growth of other Pseudonocardia that may seek to take over the ant cuticle. Resident Pseudonocardia strains inhibited $\sim 60 \%$ of tested intruder strains, and most strongly inhibited intruders that were genetically distant from the resident strain, including strains from other fungus-growing ant species and non-ant environments (Poulsen et al., 2007). This pattern may result from genetically related Pseudonocardia possessing similar BGCs, and therefore similar resistance genes that are often genetically linked to these BGCs. Two Pseudonocardia isolates, $\mathrm{BCI} 1$ and $\mathrm{BCI} 2$, were isolated from A. dentigerum ants collected on Barro Colorado Island (BCI), located in the middle of the Panama Canal. These strains shared $100 \%$ identical $16 \mathrm{~S}$ rRNA genes and $>98 \%$ average nucleotide identity between their chromosomes (Van Arnam et al., 2015). However, only strain BCI2 inhibited all other tested actinomycete strains due its unique acquisition of a BGC that encoded for an analog of the antimicrobial metabolite rebeccamycin on a plasmid that was otherwise $>96 \%$ conserved in strain BCI1. The presence of this novel plasmid-encoded BGC suggests that strain BCI2 acquired these genes horizontally 


\section{A Vertical Pseudonocardia transmission within a colony}

\section{c Horizontal Pseudonocardia transmission during colony founding}
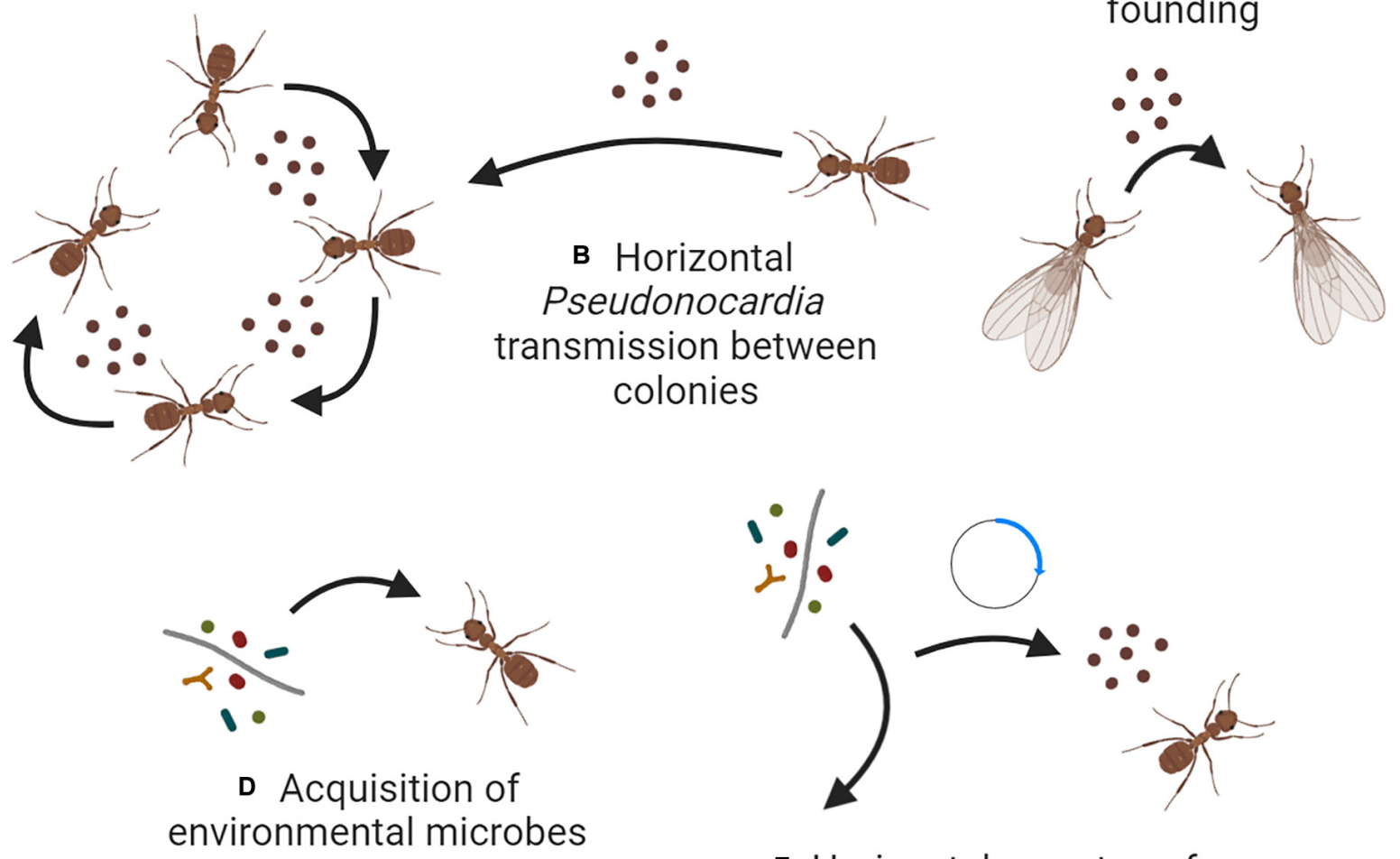

B Horizontal
Pseudonocardia
colonies

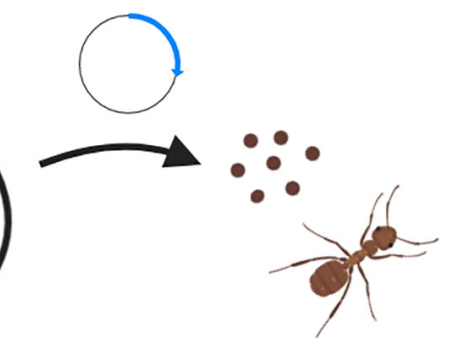

\section{E Horizontal gene transfer from transient environmental microbes}

FIGURE 2 | Ecological and evolutionary mechanisms that may govern the diversity of Pseudonocardia fungus-growing ant symbionts. Scenarios (A-C) all describe transmission involving other Pseudonocardia symbionts, either vertically within an established ant colony (A), horizontally between established colonies (B), or during colony founding (C). Scenario (D) describes the acquisition of new symbionts from the external environment, and scenario (E) describes the horizontal transfer of genes from those environmental microbes without acquisition of the microbes themselves. Note that the experimental evidence supporting each scenario varies. Figure created with BioRender.com.

from environmental actinomycetes. Similarly, Chang et al. (2020) recently isolated thiopeptide GE37468 from Trachymyrmex septentrionalis ants, whose BGC was closely related to that of the non-symbiotic Streptomyces strain ATCC 55365. It is therefore, likely that Pseudonocardia symbionts acquire BGCs from environmental actinomycetes.

\section{PSSEUDONOCARDIA AS A RESOURCE FOR NOVEL METABOLITE DISCOVERY}

Both known and unknown antimicrobials have been identified from Pseudonocardia symbionts of fungus-growing ants and the antibiotics GE37468 (Chang et al., 2020), X-14881 E, and 6-deoxy-9-O-methylrabelomycin (Carr et al., 2012). Novel metabolites discovered from Pseudonocardia symbionts include the antibiotics pseudonocardone A, B, and C (Carr et al., 2012), and 9-methoxyrebeccamycin (Van Arnam et al., 2015), the depsipeptide natural products dentigerumycin (Oh et al.,
2009) and gerumycin A, B, and C (Sit et al., 2015), nystatinlike antifungals (Barke et al., 2010; Seipke et al., 2012; Holmes et al., 2016), and the atypical antifungal polyene selvamicin (Van Arnam et al., 2016). The variable genetic contexts in which the BGCs encoding for these metabolites occur is striking. The gerumycin BGC is encoded chromosomally in one Pseudonocardia strain but on the plasmid of another (Sit et al., 2015); the same is true for selvamicin (Van Arnam et al., 2016). This suggests that Pseudonocardia strains may horizontally acquire BGCs first on their plasmids, and then later move them to their chromosome. Alternatively, BGCs could move from the chromosome to plasmid(s), with either mechanism generating high levels of BGC diversity on plasmids that might be a fruitful target for the discovery of novel metabolites (Sit et al., 2015; Ruzzini and Clardy, 2016).

Pseudonocardia symbionts also vary in their BGC composition over local geographic scales. BGC composition varied between strains sampled across a $20 \mathrm{~km}$ transect in Panama (Mcdonald et al., 2019). Of the 27 BGC families identified 
from these Pseudonocardia symbionts, 7 occurred only on BCI. Pseudonocardia symbiont strains obtained from BCI also displayed local adaptation to the Escovopsis strains that were endemic to that location (Caldera et al., 2019), suggesting that this may be a hotspot for evolving antifungal bioactivities. Other such hotspots likely exist throughout fungus-growing ant biodiversity and could also be targeted for the discovery of novel metabolites.

\section{CONCLUSION}

Having been initially established multiple times ( $\mathrm{Li}$ et al., 2018), the fungus-growing ant-Pseudonocardia symbiosis now evolves simultaneously on multiple organizational levels. First, Pseudonocardia strains are occasionally transferred horizontally between colonies, despite the predominance of vertical transmission between ants and ant colonies (Figures 2A,B). Although data is lacking, such transfer may most likely occur during colony founding when the source populations of Pseudonocardia are small and therefore, more prone to stochastic variation (Figure 2C; cf. Poulsen et al., 2009). Transfer between colonies may also be facilitated by antibiotics that

\section{REFERENCES}

Andersen, S. B., Hansen, L. H., Sapountzis, P., Sørensen, S. J., and Boomsma, J. J. (2013). Specificity and stability of the Acromyrmex-Pseudonocardia symbiosis. Mol. Ecol. 22, 4307-4321. doi: 10.1111/mec.12380

Andersen, S. B., Yek, S. H., Nash, D. R., and Boomsma, J. J. (2015). Interaction specificity between leaf-cutting ants and vertically transmitted Pseudonocardia bacteria. BMC Evol. Biol. 15:27. doi: 10.1186/s12862-015-0308-2

Armitage, S. A. O., Broch, J. F., Marín, H. F., Nash, D. R., and Boomsma, J. J. (2011). Immune defense in leaf-cutting ants: a cross-fostering approach. Evolution 65, 1791-1799. doi: 10.1111/j.1558-5646.2011.01241.x

Barke, J., Seipke, R. F., Grüschow, S., Heavens, D., Drou, N., Bibb, M. J., et al. (2010). A mixed community of actinomycetes produce multiple antibiotics for the fungus farming ant Acromyrmex octospinosus. BMC Biol. 8:109. doi: 10.1186/1741-7007-8-109

Bennett, G. M., and Moran, N. A. (2015). Heritable symbiosis: the advantages and perils of an evolutionary rabbit hole. Proc. Natl. Acad. Sci. U.S.A. 112, 10169-10176. doi: 10.1073/pnas.1421388112

Cafaro, M. J., and Currie, C. R. (2005). Phylogenetic analysis of mutualistic filamentous bacteria associated with fungus-growing ants. Can. J. Microbiol. 446, 441-446. doi: 10.1139/W05-023

Cafaro, M. J., Poulsen, M., Little, A. E. F., Price, S. L., Gerardo, N. M., Wong, B., et al. (2011). Specificity in the symbiotic association between fungus-growing ants and protective Pseudonocardia bacteria. Proc. R. Soc. B Biol. Sci. 278, 1814-1822. doi: 10.1098/rspb.2010.2118

Caldera, E. J., Chevrette, M. G., McDonald, B. R., and Currie, C. R. (2019). Local adaptation of bacterial symbionts within a geographic mosaic of antibiotic coevolution. Appl. Environ. Microbiol. 85:e01580-19. doi: 10.1128/AEM.01 580-19

Caldera, E. J., and Currie, C. R. (2012). The population structure of antibioticproducing bacterial symbionts of Apterostigma dentigerum ants: impacts of coevolution and multipartite symbiosis. Am. Nat. 180, 604-617. doi: 10.1086/ 667886

Carr, G., Derbyshire, E. R., Caldera, E., Currie, C. R., and Clardy, J. (2012). Antibiotic and antimalarial quinones from fungus-growing antassociated Pseudonocardia sp. J. Nat. Prod. 75, 1806-1809. doi: 10.1021/np30 $0380 \mathrm{t}$

Chang, P. T., Rao, K., Longo, L. O., Lawton, E. S., Scherer, G., and Van Arnam, E. B. (2020). Thiopeptide defense by an ant's bacterial symbiont. J. Nat. Prod. 83, 725-729. doi: 10.1021/acs.jnatprod.9b00897 allow invasion that overcomes native Pseudonocardia strains (Poulsen et al., 2007; Van Arnam et al., 2015). Second, nichedefining genes such as secondary metabolite BGCs may be horizontally transferred to Pseudonocardia from other microbes that pass through its ant-associated niche, and such transfer likely involves plasmids as a prominent mechanism of genome plasticity (Figures 2D,E; Van Arnam et al., 2015). Together, these mechanisms allow Pseudonocardia symbionts to avoid Mueller's ratchet and maintain their effectiveness as defensive mutualists of fungus-growing ants.

\section{AUTHOR CONTRIBUTIONS}

SG and JK conceived, wrote, and revised this manuscript. Both authors contributed to the article and approved the submitted version.

\section{FUNDING}

Funding for this work was provided by NSF IOS-1656475.

Chevrette, M. G., Carlson, C. M., Ortega, H. E., Thomas, C., Ananiev, G. E., Barns, K. J., et al. (2019). The antimicrobial potential of Streptomyces from insect microbiomes. Nat. Commun. 10:516. doi: 10.1038/s41467-019-08438-0

Chevrette, M. G., and Currie, C. R. (2019). Emerging evolutionary paradigms in antibiotic discovery. J. Ind. Microbiol. Biotechnol. 46, 257-271. doi: 10.1007/ s10295-018-2085-6

Clardy, J., Fischbach, M. A., and Currie, C. R. (2009). The natural history of antibiotics. Curr. Biol. 19, 437-441. doi: 10.1016/j.cub.2009.04.001

Currie, C. R., Bot, A. N. M., and Boomsma, J. J. (2003a). Experimental evidence of a tripartite mutualism: bacteria protect ant fungus gardens from specialized parasites. Oikos 101, 91-102. doi: 10.1034/j.1600-0706.2003.12036.x

Currie, C. R., Mueller, U. G., and Malloch, D. (1999a). The agricultural pathology of ant fungus gardens. Proc. Natl. Acad. Sci. U.S.A. 96, 7998-8002. doi: 10.1073/ pnas.96.14.7998

Currie, C. R., Scott, J. A., Summerbell, R. C., and Malloch, D. (2003b). Corrigenda: fungus-growing ants use antibiotic-producing bacteria to control garden parasites. Nature 423:461. doi: 10.1038/nature01563

Currie, C. R., Scott, J. A., Summerbell, R. C., and Malloch, D. (1999b). Fungusgrowing ants use antibiotic-producing bacteria to control garden parasites. Nature 398, 701-705. doi: 10.1038/19519

Currie, C. R., Wong, B., Stuart, A. E., Schultz, T. R., Rehner, S. A., Mueller, U. G., et al. (2003c). Ancient tripartite coevolution in the attine ant-microbe symbiosis. Science 299, 386-388. doi: 10.1126/science.1078155

Currie, C. R., Poulsen, M., Mendenhall, J., Boomsma, J. J., and Billen, J. (2006). Coevolved crypts and exocrine glands support mutualistic bacteria in fungusgrowing ants. Science 311, 81-83. doi: 10.1126/science.1119744

Currie, C. R., and Stuart, A. E. (2001). Weeding and grooming of pathogens in agriculture by ants. Proc. R. Soc. B Biol. Sci. 268, 1033-1039. doi: 10.1098/rspb. 2001.1605

Dângelo, R. A. C., de Souza, D. J., Mendes, T. D., Couceiro, J. D. C., and Lucia, T. M. C. D. (2016). Actinomycetes inhibit filamentous fungi from the cuticle of Acromyrmex leafcutter ants. J. Basic Microbiol. 56, 229-237. doi: 10.1002/jobm. 201500593

De Fine Licht, H. H., and Boomsma, J. J. (2010). Forage collection, substrate preparation, and diet composition in fungus-growing ants. Ecol. Entomol. 35, 259-269. doi: 10.1111/j.1365-2311.2010.01193.x

de Souza, D. J., Lenoir, A., Kasuya, M. C. M., Ribeiro, M. M. R., Devers, S., Couceiro, J. D. C., et al. (2013). Ectosymbionts and immunity in the leaf-cutting ant Acromyrmex subterraneus subterraneus. Brain. Behav. Immun. 28, 182-187. doi: 10.1016/j.bbi.2012.11.014 
Fernández-Marín, H., Bruner, G., Gomez, E. B., Nash, D. R., Boomsma, J. J., and Wcislo, W. T. (2013). Dynamic disease management in Trachymyrmex fungus-growing ants (Attini: Formicidae). Am. Nat. 181, 571-582. doi: 10.1086/ 669664

Garcia, J. R., and Gerardo, N. M. (2014). The symbiont side of symbiosis: Do microbes really benefit? Front. Microbiol. 5:510. doi: 10.3389/fmicb.2014.00510

Gemperline, E., Horn, H. A., Delaney, K., Currie, C. R., and Li, L. (2017). Imaging with mass spectrometry of bacteria on the exoskeleton of fungus-growing ants. ACS Chem. Biol. 12, 1980-1985. doi: 10.1021/acschembio.7b00038

Gillespie, J. P., Kanost, M. R., and Trenczek, T. (1997). Biological mediators of insect immunity. Annu. Rev. Entomol. 42, 611-643. doi: 10.1146/annurev.ento. 42.1.611

Haeder, S., Wirth, R., Herz, H., and Spiteller, D. (2009). Candicidin-producing Streptomyces support leaf-cutting ants to protect their fungus garden against the pathogenic fungus Escovopsis. Proc. Natl. Acad. Sci. U.S.A. 106, 4742-4746. doi: $10.1073 /$ pnas.0812082106

Hölldobler, B., and Wilson, E. O. (1990). The Ants. Cambridge, MA: Belknap Press.

Holmes, N., Innocent, T., Heine, D., Al Bassam, M., Worsley, S., Trottmann, F., et al. (2016). Genome analysis of two Pseudonocardia phylotypes associated with Acromyrmex leafcutter ants reveals their biosynthetic potential. Front. Microbiol. 7:2073. doi: 10.3389/fmicb.2016.02073

Hughes, D. P., Evans, H. C., Hywel-Jones, N., Boomsma, J. J., and Armitage, S. A. O. (2009). Novel fungal disease in complex leaf-cutting ant societies. Ecol. Entomol. 34, 214-220. doi: 10.1111/j.1365-2311.2008.01066.x

Hughes, W. O. H., Thomsen, L., Eilenberg, J., and Boomsma, J. J. (2004). Diversity of entomopathogenic fungi near leaf-cutting ant nests in a neotropical forest, with particular reference to Metarhizium anisopliae var. anisopliae. J. Invertebr. Pathol. 85, 46-53. doi: 10.1016/j.jip.2003.12.005

Ishak, H. D., Miller, J. L., Sen, R., Dowd, S. E., Meyer, E., and Mueller, U. G. (2011). Microbiomes of ant castes implicate new microbial roles in the fungusgrowing ant Trachymyrmex septentrionalis. Sci. Rep. 1:204. doi: 10.1038/srep 00204

Klassen, J. L. (2014). Microbial secondary metabolites and their impacts on insect symbioses. Curr. Opin. Insect Sci. 4, 15-22. doi: 10.1016/j.cois.2014.08.004

Klassen, J. L. (2018). Defining microbiome function. Nat. Microbiol. 3, 864-869. doi: 10.1038/s41564-018-0189-4

Klassen, J. L. (2020). Ecology helps bound causal explanations in microbiology. Biol. Philos. 35:3. doi: 10.1007/s10539-019-9728-5

Kost, C., Lakatos, T., Böttcher, I., Arendholz, W.-R., Redenbach, M., and Wirth, R. (2007). Non-specific association between filamentous bacteria and fungusgrowing ants. Naturwissenschaften 94, 821-828. doi: 10.1007/s00114-007$0262-y$

Li, H., Sosa-Calvo, J., Horn, H. A., Pupo, M. T., Clardy, J., Rabeling, C., et al. (2018). Convergent evolution of complex structures for ant-bacterial defensive symbiosis in fungus-farming ants. Proc. Natl. Acad. Sci. U.S.A. 115, 1072010725. doi: 10.1073/pnas. 1809332115

Little, A. E. F., and Currie, C. R. (2007). Symbiotic complexity: discovery of a fifth symbiont in the attine ant-microbe symbiosis. Biol. Lett. 3, 501-504. doi: $10.1098 / \mathrm{rsbl} .2007 .0253$

Little, A. E. F., and Currie, C. R. (2008). Black yeast symbionts compromise the efficiency of antibiotic defenses in fungus-growing ants. Ecology 89, 1216-1222. doi: 10.1890/07-0815.1

Marsh, S. E., Poulsen, M., Gorosito, N. B., Pinto-Tomás, A., Masiulionis, V. E., and Currie, C. R. (2013). Association between Pseudonocardia symbionts and Atta leaf-cutting ants suggested by improved isolation methods. Int. Microbiol. 16, 17-25. doi: 10.2436/20.1501.01.176

Marsh, S. E., Poulsen, M., Pinto-Tomás, A., and Currie, C. R. (2014). Interaction between workers during a short time window is required for bacterial symbiont transmission in Acromyrmex leaf-cutting ants. PLoS One 9:e103269. doi: 10. 1371/journal.pone.0103269

Mattoso, T. C., Moreira, D. D. O., and Samuels, R. I. (2012). Symbiotic bacteria on the cuticle of the leaf-cutting ant Acromyrmex subterraneus subterraneus protect workers from attack by entomopathogenic fungi. Biol. Lett. 8, 461-464. doi: 10.1098/rsbl.2011.0963

Mcdonald, B. R., Chevrette, M. G., Klassen, J. L., Horn, H. A., Caldera, E. J., WendtPienkowski, E., et al. (2019). Biogeography and microscale diversity shape the biosynthetic potential of fungus-growing ant-associated Pseudonocardia. bioRxiv [Preprint]. doi: 10.1101/545640
Meirelles, L. A., Mendes, T. D., Solomon, S. E., Bueno, O. C., Pagnocca, F. C., and Rodrigues, A. (2013). Broad Escovopsis-inhibition activity of Pseudonocardia associated with Trachymyrmex ants. Environ. Microbiol. Rep. 6, 339-345. doi: 10.1111/1758-2229.12132

Mikheyev, A. S., Vo, T., and Mueller, U. G. (2008). Phylogeography of postPleistocene population expansion in a fungus-gardening ant and its microbial mutualists. Mol. Ecol. 17, 4480-4488. doi: 10.1111/j.1365-294X.2008.03940.x

Mueller, U. G., Dash, D., Rabeling, C., and Rodrigues, A. (2008). Coevolution between attine ants and actinomycete bacteria: a reevaluation. Evolution 62, 2894-2912. doi: 10.1111/j.1558-5646.2008.00501.x

Mueller, U. G., Ishak, H., Lee, J. C., Sen, R., and Gutell, R. R. (2010). Placement of attine ant-associated Pseudonocardia in a global Pseudonocardia phylogeny (Pseudonocardiaceae, Actinomycetales): a test of two symbiont-association models. Antonie Van Leeuwenhoek 98, 195-212. doi: 10.1007/s10482-0109427-3

Mueller, U. G., Rehner, S. A., and Schultz, T. R. (1998). The evolution of agriculture in ants. Science 281, 2034-2038. doi: 10.1126/science.281.5385.2034

Oh, D.-C., Poulsen, M., Currie, C. R., and Clardy, J. (2009). Dentigerumycin: a bacterial mediator of an ant-fungus symbiosis. Nat. Chem. Biol. 5, 391-393. doi: $10.1038 /$ nchembio. 159

Poulsen, M., Bot, A. N. M., Currie, C. R., Nielsen, M. G., and Boomsma, J. J. (2003). Within-colony transmission and the cost of transmission in the leaf-cutting bacterium a mutualistic ant Acromyrmex octospinosus. Funct. Ecol. 17, 260-269. doi: 10.1046/j.1365-2435.2003.00726.x

Poulsen, M., Cafaro, M., Boomsma, J. J., and Currie, C. R. (2005). Specificity of the mutualistic association between actinomycete bacteria and two sympatric species of Acromyrmex leaf-cutting ants. Mol. Ecol. 14, 3597-3604. doi: 10.1111/ j.1365-294X.2005.02695.x

Poulsen, M., Cafaro, M. J., Erhardt, D. P., Little, A. E. F., Gerardo, N. M. Tebbets, B., et al. (2010). Variation in Pseudonocardia antibiotic defence helps govern parasite-induced morbidity in Acromyrmex leaf-cutting ants. Environ. Microbiol. Rep. 2, 534-540. doi: 10.1111/j.1758-2229.2009.00098.x

Poulsen, M., Erhardt, D. P., Molinaro, D. J., Lin, T.-L., and Currie, C. R. (2007). Antagonistic bacterial interactions help shape host-symbiont dynamics within the fungus-growing ant-microbe mutualism. PLoS One 2:e960. doi: 10.1371/ journal.pone. 0000960

Poulsen, M., Fernández-Marín, H., Currie, C. R., and Boomsma, J. J. (2009). Ephemeral windows of opportunity for horizontal transmission of fungal symbionts in leaf-cutting ants. Evolution 63, 2235-2247. doi: 10.1111/j.15585646.2009.00704.x

Poulsen, M., Maynard, J., Roland, D. L., and Currie, C. R. (2011). The role of symbiont genetic distance and potential adaptability in host preference towards Pseudonocardia symbionts in Acromyrmex leaf-cutting ants. J. Insect Sci. 11:120. doi: 10.1673/031.011.12001

Rodrigues, A., Bacci, M. Jr., Mueller, U. G., Ortiz, A., and Pagnocca, F. C. (2008). Microfungal "weeds" in the leafcutter ant symbiosis. Microb. Ecol. 56, 604-614. doi: $10.1007 / \mathrm{s} 00248-008-9380-0$

Ruzzini, A. C., and Clardy, J. (2016). Gene flow and molecular innovation in bacteria. Curr. Biol. 26, R859-R864. doi: 10.1016/j.cub.2016.08.004

Sachs, J. L., Skophammer, R. G., and Regus, J. U. (2011). Evolutionary transitions in bacterial symbiosis. Proc. Natl. Acad. Sci. U.S.A. 108, 10800-10807. doi: 10.1073/pnas. 1100304108

Scheuring, I., and Yu, D. W. (2012). How to assemble a beneficial microbiome in three easy steps. Ecol. Lett. 15, 1300-1307. doi: 10.1111/j.1461-0248.2012. 01853.x

Schoenian, I., Spiteller, M., Ghaste, M., Wirth, R., Herz, H., and Spiteller, D. (2011). Chemical basis of the synergism and antagonism in microbial communities in the nests of leaf-cutting ants. Proc. Natl. Acad. Sci. U.S.A. 108, 1955-1960. doi: $10.1073 /$ pnas. 1008441108

Schultz, T. R., and Brady, S. G. (2008). Major evolutionary transitions in ant agriculture. Proc. Natl. Acad. Sci. U.S.A. 105, 5435-5440. doi: 10.1073/pnas. 0711024105

Seipke, R. F., Grüschow, S., Goss, R. J. M., and Hutchings, M. I. (2012). Isolating antifungals from fungus-growing ant symbionts using a genomeguided chemistry approach. Methods Enzymol. 517, 47-70. doi: 10.1016/B9780-12-404634-4.00003-6

Sen, R., Ishak, H. D., Estrada, D., Dowd, S. E., Hong, E., and Mueller, U. G. (2009). Generalized antifungal activity and 454-screening of Pseudonocardia 
and Amycolatopsis bacteria in nests of fungus-growing ants. Proc. Natl. Acad. Sci. U.S.A. 106, 17805-17810. doi: 10.1073/pnas.0904827106

Sit, C. S., Ruzzini, A. C., Van Arnam, E. B., Ramadhar, T. R., Currie, C. R., and Clardy, J. (2015). Variable genetic architectures produce virtually identical molecules in bacterial symbionts of fungus-growing ants. Proc. Natl. Acad. Sci. U.S.A. 112, 13150-13154. doi: 10.1073/pnas.1515348112

Sosa-Calvo, J., Schultz, T. R., JeŠovnik, A., Dahan, R. A., and Rabeling, C. (2018). Evolution, systematics, and natural history of a new genus of cryptobiotic fungus-growing ants. Syst. Entomol. 43, 549-567. doi: 10.1111/syen.12289

Toft, C., and Andersson, S. G. E. (2010). Evolutionary microbial genomics: insights into bacterial host adaptation. Nat. Rev. Genet. 11, 465-475. doi: 10.1038/ $\operatorname{nrg} 2798$

Van Arnam, E. B., Currie, C. R., and Clardy, J. (2018). Defense contracts: molecular protection in insect-microbe symbioses. Chem. Soc. Rev. 47, 1638-1651. doi: $10.1039 / \mathrm{c} 7 \mathrm{cs} 00340 \mathrm{~d}$

Van Arnam, E. B., Ruzzini, A. C., Sit, C. S., Currie, C. R., and Clardy, J. (2015). A rebeccamycin analog provides plasmid-encoded niche defense. J. Am. Chem. Soc. 137, 14272-14274. doi: 10.1021/jacs.5b09794

Van Arnam, E. B., Ruzzini, A. C., Sit, C. S., Horn, H., Pinto-Tomás, A. A., Currie, C. R., et al. (2016). Selvamicin, an atypical antifungal polyene from two alternative genomic contexts. Proc. Natl. Acad. Sci. U.S.A. 113, 12940-12945. doi: 10.1073/pnas.1613285113
Walker, T. N., and Hughes, W. O. H. (2009). Adaptive social immunity in leaf-cutting ants. Biol. Lett. 5, 446-448. doi: 10.1098/rsbl.2009.0107

Weber, N. A. (1972). Gardening Ants - The Attines. Philadelphia, PA: The American Philosophical Society.

Woolhouse, M. E. J., Webster, J. P., Domingo, E., Charlesworth, B., and Levin, B. R. (2002). Biological and biomedical implications of the co-evolution of pathogens and their hosts. Nat. Genet. 32, 569-577. doi: 10.1038/ng1202-569

Zhang, M. M., Poulsen, M., and Currie, C. R. (2007). Symbiont recognition of mutualistic bacteria by Acromyrmex leaf-cutting ants. ISME J. 1, 313-320. doi: 10.1038/ismej.2007.41

Conflict of Interest: The authors declare that the research was conducted in the absence of any commercial or financial relationships that could be construed as a potential conflict of interest.

Copyright $\odot 2020$ Goldstein and Klassen. This is an open-access article distributed under the terms of the Creative Commons Attribution License (CC BY). The use, distribution or reproduction in other forums is permitted, provided the original author(s) and the copyright owner(s) are credited and that the original publication in this journal is cited, in accordance with accepted academic practice. No use, distribution or reproduction is permitted which does not comply with these terms. 